\title{
A new heat transfer analysis in machining based on two steps of 3D finite element modelling and experimental validation
}

\author{
B. Haddag $\cdot$ T. Kagnaya $\cdot$ M. Nouari $\cdot$ \\ T. Cutard
}

\begin{abstract}
Modelling machining operations allows estimating cutting parameters which are difficult to obtain experimentally and in particular, include quantities characterizing the tool-workpiece interface. Temperature is one of these quantities which has an impact on the tool wear, thus its estimation is important. This study deals with a new modelling strategy, based on two steps of calculation, for analysis of the heat transfer into the cutting tool. Unlike the classical methods, considering only the cutting tool with application of an approximate heat flux at the cutting face, estimated from experimental data (e.g. measured cutting force, cutting power), the proposed approach consists of two successive 3D Finite Element calculations and fully independent on the experimental measurements; only the definition of the behaviour of the tool-workpiece couple is necessary. The first one is a $3 \mathrm{D}$ thermomechanical modelling of the chip formation process, which allows estimating cutting forces, chip morphology and its flow direction. The second calculation is a $3 \mathrm{D}$ thermal modelling of the heat diffusion into the cutting tool, by using an adequate thermal loading (applied uniform or non-uniform heat flux). This loading is estimated using some quantities obtained from the first step calculation, such as contact pressure, sliding velocity distributions and contact area. Comparisons in one hand between experimental data and
\end{abstract}

B. Haddag $(\bowtie) \cdot$ T. Kagnaya $\cdot$ M. Nouari

Laboratoire d'Énergétique et de Mécanique Théorique et

Appliquée, Université de Lorraine, LEMTA CNRS-UMR

7563, Mines Nancy, GIP-InSIC, 27 rue d'Hellieule,

88100 St-Dié-des-Vosges, France

e-mail: badis.haddag@insic.fr

T. Kagnaya $\cdot$ T. Cutard

Mines Albi, ICA (Institut Clément Ader),

Université de Toulouse, Campus

Jarlard, 81013 Albi cedex 09, France the first calculation and at the other hand between measured temperatures with embedded thermocouples and the second calculation show a good agreement in terms of cutting forces, chip morphology and cutting temperature.

\section{List of symbols}

\section{Cutting parameters}

$V_{c} \quad$ Cutting speed $(\mathrm{m} / \mathrm{min})$

$f \quad$ Feed rate $(\mathrm{mm} / \mathrm{tr})$

ap Depth of cut (mm)

$\kappa_{r} \quad$ Approach angle $\left(^{\circ}\right)$

$\gamma_{o}$ Tool-rake angle $\left(^{\circ}\right)$

$\lambda_{s} \quad$ Inclination angle $\left(^{\circ}\right)$

$\alpha_{o} \quad$ Clearance angle $\left(^{\circ}\right)$

$F_{c} \quad$ Cutting cut force component $(\mathrm{N})$

$F_{f} \quad$ Feed force component (N)

$F_{p} \quad$ Depth of cut force component (N)

$F_{R} \quad$ Resultant cutting force (N)

\section{Mechanical quantities}

$\sigma \quad$ Cauchy stress tensor (MPa)

$f_{v} \quad$ Body force density vector $\left(\mathrm{N} / \mathrm{m}^{3}\right)$

$\ddot{u} \quad$ Acceleration vector $\left(\mathrm{m} / \mathrm{s}^{2}\right)$

$\rho \quad$ Material density $\left(\mathrm{kg} / \mathrm{m}^{3}\right)$

E Young modulus (GPa)

$v \quad$ Poisson's ratio

$A \quad$ Initial uniaxial tension stress at reference equivalent plastic strain-rate and reference temperature of the workmaterial (MPa)

$B \quad$ Strain hardening parameter of the workmaterial (MPa)

$n \quad$ Strain hardening exponent parameter of the workmaterial

C Strain-rate sensitivity parameter of the workmaterial 
Temperature sensitivity parameter of the workmaterial

$\bar{\varepsilon}^{p} \quad$ von Mises equivalent plastic strain

$\dot{\bar{\varepsilon}}^{p} \quad$ von Mises equivalent plastic strain-rate

$\dot{\bar{\varepsilon}}_{0} \quad$ Reference equivalent plastic strain-rate

$\bar{\sigma} \quad$ von Mises equivalent stress (MPa)

$\sigma_{n} \quad$ Normal friction stress (MPa)

$\tau_{f} \quad$ Shear friction stress (MPa)

$\mu \quad$ Friction coefficient

$\tau_{\max } \quad$ Shear stress limit (MPa)

$\bar{\tau}_{f} \quad$ Average sliding stress at the tool-chip interface (MPa)

$\bar{\gamma} \quad$ Average sliding velocity at the tool-workpiece interface $(\mathrm{m} / \mathrm{s})$

$\tau_{(x, y)} \quad$ Local sliding stress at the tool-workpiece interface (MPa)

$\dot{\gamma}(x, y) \quad$ Local sliding velocity at the tool-workpiece interface $(\mathrm{m} / \mathrm{s})$

$U_{x} \quad$ Displacement along the $\mathrm{x}$ axis

$U_{y} \quad$ Displacement along the y axis

$U_{z} \quad$ Displacement along the $\mathrm{z}$ axis

\section{Thermal quantities}

\section{$T \quad$ Temperature $\left({ }^{\circ} \mathrm{C}\right)$}

$T_{0} \quad$ Reference ambient temperature $\left({ }^{\circ} \mathrm{C}\right)$

$T_{m} \quad$ Workmaterial melting temperature $\left({ }^{\circ} \mathrm{C}\right)$

$T_{\text {env }} \quad$ Environment temperature $\left({ }^{\circ} \mathrm{C}\right)$

$T_{\text {tool }} \quad$ Tool temperature $\left({ }^{\circ} \mathrm{C}\right)$

$T_{\text {hold }} \quad$ Toolholder temperature $\left({ }^{\circ} \mathrm{C}\right)$

$T_{\text {int-w }} \quad$ Interface workpiece temperature $\left({ }^{\circ} \mathrm{C}\right)$

$T_{\text {int } t} \quad$ Interface tool temperature $\left({ }^{\circ} \mathrm{C}\right)$

$\lambda$ Thermal conductivity $\left(\mathrm{W} / \mathrm{m} /{ }^{\circ} \mathrm{C}\right)$

$c_{p} \quad$ Specific heat capacity $\left(\mathrm{J} / \mathrm{kg} /{ }^{\circ} \mathrm{C}\right)$

$\alpha \quad$ Thermal expansion $\left(\mu \mathrm{m} / \mathrm{m} /{ }^{\circ} \mathrm{C}\right)$

$\eta_{p} \quad$ Plastic work conversion factor (TaylorQuinney factor)

$f_{f} \quad$ Fraction of the friction energy conducted into the tool

$h \quad$ Heat transfer coefficient for the tool-wokpiece interface $\left(\mathrm{kW} / \mathrm{m}^{2} /{ }^{\circ} \mathrm{C}\right)$

$h_{\text {env-tool }} \quad$ Heat transfer coefficient for the tool-environment interface $\left(\mathrm{W} / \mathrm{m}^{2} /{ }^{\circ} \mathrm{C}\right)$

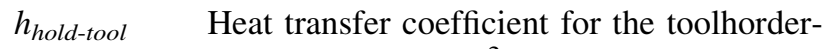
tool interface $\left(\mathrm{W} / \mathrm{m}^{2} /{ }^{\circ} \mathrm{C}\right)$

$\dot{q}_{v} \quad$ Volumetric heat generation in the workmaterial $\left(\mathrm{W} / \mathrm{m}^{3}\right)$

$\dot{q}_{p} \quad$ Volumetric heat generation due to plastic work $\left(\mathrm{W} / \mathrm{m}^{3}\right)$

$\dot{q}_{f} \quad$ Frictional heat flux at the tool-workpiece interface $\left(\mathrm{W} / \mathrm{m}^{2}\right)$

$\dot{q}_{c} \quad$ Heat conduction flux at the tool-workpiece interface $\left(\mathrm{W} / \mathrm{m}^{2}\right)$ $\dot{q}_{\rightarrow \text { tool }} \quad$ Heat flux going into the tool at the toolworkpiece interface $\left(\mathrm{W} / \mathrm{m}^{2}\right)$

$\dot{q}_{\rightarrow \text { workpiece }}$ Heat flux going into the workpiece at the tool-workpiece interface $\left(\mathrm{W} / \mathrm{m}^{2}\right)$

$\dot{q}_{\rightarrow e n v} \quad$ Heat flux at the tool-environment interface $\left(\mathrm{W} / \mathrm{m}^{2}\right)$

$\dot{q}_{\rightarrow \text { hold }} \quad$ Heat flux at the toolholder-tool interface $\left(\mathrm{W} / \mathrm{m}^{2}\right)$

$\overline{\dot{q}}_{\rightarrow \text { tool }} \quad$ Applied uniform heat flux on the tool rake face $\left(\mathrm{W} / \mathrm{m}^{2}\right)$

$\dot{q}_{\rightarrow \text { tool }}(x, y) \quad$ Applied non-uniform heat flux on the tool rake face $\left(\mathrm{W} / \mathrm{m}^{2}\right)$

\section{Introduction}

In machining processes, the development of accurate models to estimate heat exchange, cutting forces and tool wear has been the subject of particular attention in scientific community. Analytical, numerical or hybrid models are developed for the analysis of different machining processes. The efficiency of each approach is related to the physical quantities that can be estimated, and also to the possibility to use such quantities to optimize or to improve the cutting operation (e.g. increasing tool life, enhancing productivity or reducing lubrication, etc.). Analytical models are generally based on several assumptions (geometrical simplifications, simple boundary conditions, simplified tool-workpiece configuration, etc.) which allow obtaining a rapid estimation of some thermomechanical quantities. Some example of such developments can be found in [1-9]. Besides, numerical models are more efficient for machining problems where complex tool geometry and/or tool-workpiece configuration should be considered. Finite Element [10-18], Difference Element $[19,20]$ and more recently Smoothed Particle Hydrodynamics [22] methods are an example of such approaches used in this case. During these last years, it seems that the Finite Element Method (FEM) is the widely used approach; while up to 90th analytical approaches are the main proposed analyses. In fact, the FEM allows treating the chip formation process with few assumptions, particularly when cutting process should be treated under the $3 \mathrm{D}$ configuration (non-orthogonal cutting conditions), as in the present work. However, compared to the analytical approaches, the high computation time remains the weak point of the FE approaches.

Cutting process is modelled considering either the toolworkpiece couple, as in [10-22], or only the cutting tool with adequate thermomechanical loading, as in [23-36]. For the first case, chip formation process is globally analysed. In several research works the problem is treated in 
orthogonal cutting configuration, with analytical, numerical or hybrid models. The main quantities estimated are the cutting force, the chip morphology and tool-chip interface characteristics (contact length/area, contact pressure, interface temperature...). Simulations with FEM in 3D case are performed recently thanks to advanced developments in remeshing techniques in commercial FE codes, like Deform $^{\mathrm{TM}}$ [37] and Abaqus ${ }^{\mathrm{TM}}$ [38], used in the present work. For the second case, since the integrity of cutting tools during machining is of particular importance (improving tool life, machined surface quality...) analysis of its behaviour is widely investigated. The developed models consider the cutting tool, with the definition of the thermomechanical loading, to analyse its behaviour during machining. One of the critical point of this analysis, irrespective of the approach followed (analytical, numerical...), is the definition of the boundary conditions, particularly the adequate thermomechanical loading in the active zone of the tool (tool-workpiece contact zone). Indeed, interface contact pressure, sliding velocity, contact area as well as some physical parameters involved in the constitutive equations (e.g. friction heat partition and interface heat transfer coefficients) should be well defined to estimate the thermomechanical loading of the cutting tool. These quantities are generally estimated from experimental measurements, combined with some analytical developments. Chang [30] developed an analyticalnumerical model for heat transfer into the tool. The model takes into account the geometry of the tool active zone of the insert to determine the friction contact area, and the friction force, in order to deduce the applied heat flux to the cutting tool (insert). Stephenson et al. [26] developed an analytical model to predict the cutting tool temperature under transient conditions. The thermal loading at the contact face of insert is treated as a spatially uniform plane heat source function of cutting time. The contact area is defined from experimental machining tests. The model is based on an analytical solution for the temperature in a rectangular insert subjected to a piecewise constant heat flux. Different thermal boundary conditions are applied to the insert to show its impact on the tool-chip interface temperature. Liu et al. [25] studied the temperature field in a milling insert with complex groove. Using analytical model and one measured temperature at an embedded thermocouple in the insert, they defined the temperature evolution with cutting time at several points at the tool-chip interface. These temperatures are then used in a developed FE model as thermal boundary conditions. Several authors developed the same modelling strategy (e.g. [23-36]), but in all treated problems a uniform applied heat flux is considered, which is not true in reality, as it can be seen in this work.

The objective of this work is the combination between the approach using the tool-workpiece couple for chip formation process analysis and that treating the cutting tool separately, with adequate thermomechanical loading. This allows to easily analysing the heat diffusion into the insert without using any measured quantities, like cutting force or cutting power for example. The modelling strategy is developed in the context of a fully 3D FEM and focused on the thermomechanical behaviour of the tool-workpiece couple. For experimental validation, a turning operation is considered. The approach allows giving the main physical quantities characterizing the cutting process exclusively from modelling, so experimental data are used only for the validation purpose. First of all, the experimental procedure is described and some experimental results are given for modelling validation. Then, the main constitutive equations for the modelling are presented. The two-steps FE-based model is then developed with the description of the chip formation process analysis (first step), followed by the modelling of heat diffusion into the insert (second-step). Finally, the obtained results from each calculation have been compared with the experimental data.

\section{Experimental aspects}

\subsection{Experimental setup}

The experimental setup consists of an instrumented turning operation using dynamometer table (Kistler ${ }^{\circledR}$ table, type 9257B) and thermocouple system (Actarus $\left.{ }^{\circledR}[39,40]\right)$, for cutting force components and temperature measurements, respectively. Note that different temperature measurement systems can be used in machining, as shown in [39-44]. The tool-workpiece configuration, machining device and experimental setup used for measurements are illustrated in Fig. 1a-c, respectively. The cutting configuration of the tool-workpiece couple is defined by the following cutting angles: approach angle $\kappa_{r}$ equal $90^{\circ}$, tool-rake $\gamma_{o}$ and inclination $\lambda_{s}$ angles equal $0^{\circ}$, and clearance angle equal $7^{\circ}$, as shown in Fig. 1a. The cutting condition that has been taken for the numerical analysis and validation is as follows:

- cutting speed: $V_{c}=250 \mathrm{~m} / \mathrm{min}$,

- feed rate: $f=0.1 \mathrm{~mm} / \mathrm{tr}$,

- depth of cut: $a p=1.1 \mathrm{~mm}$.

The cutting tool is a triangular uncoated insert, of a WC-6\%Co material (cemented tungsten carbide with $6 \%$ of cobalt as binder phase), designated by TCMW16T304. The insert and its dimension characteristics are shown, respectively, in Fig. 2a, b, the microstructure of the insert material is shown in Fig. 2c, while the chemical composition is given in Table 1.

The workpiece is a bar of the ferrite-perlite steel AISI 1045, with diameter of $90 \mathrm{~mm}$, commonly used in industry 
Fig. 1 a Tool-workpiece configuration, $\mathbf{b}$ machining device, and $\mathbf{c}$ experimental setup used for the analysis [23] (a)

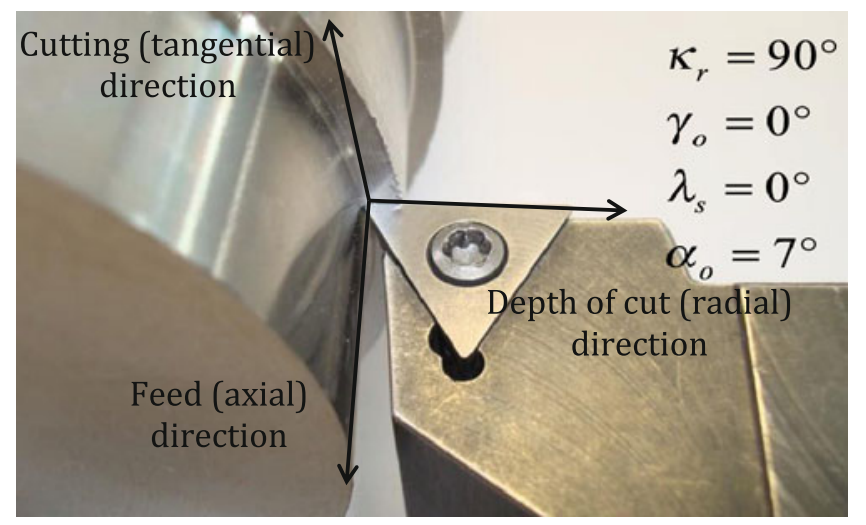

(b)

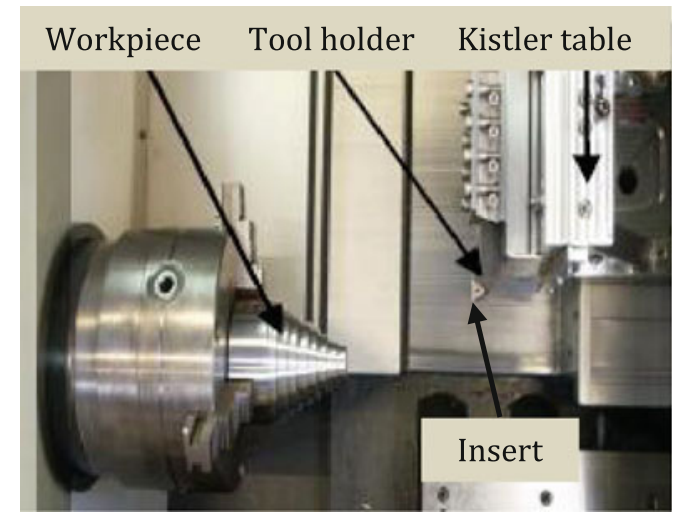

(c)

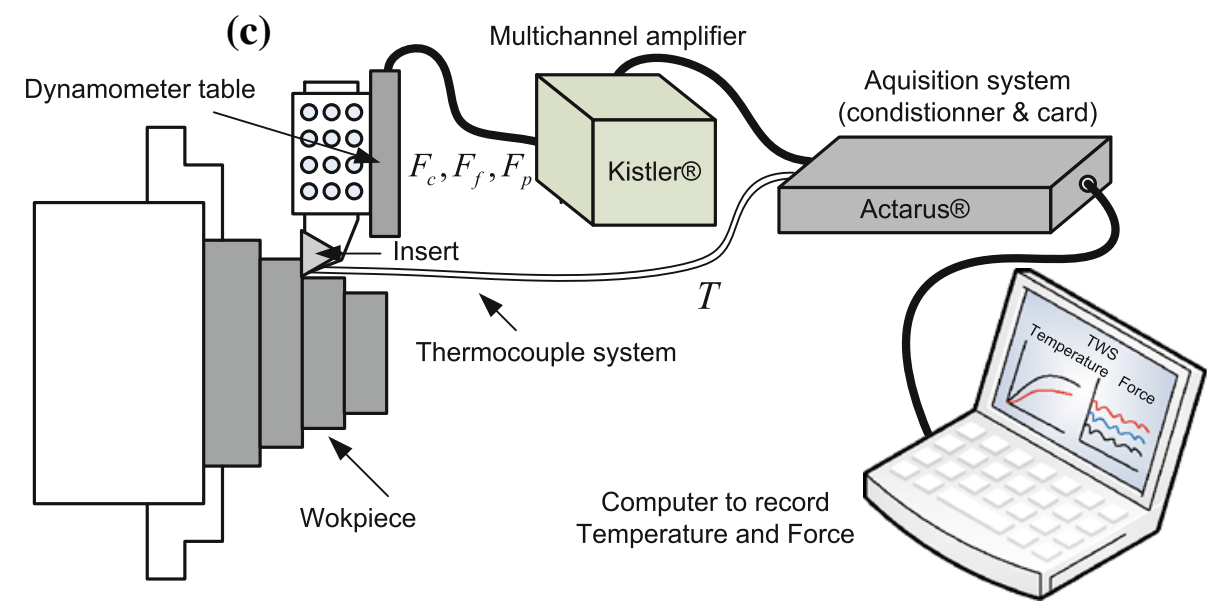

(aerospace, automotive, mechanical). The microstructure of this material is shown in Fig. 3 and its chemical composition is given in Table 2 .

To measure the cutting temperature at two points close to the tool-rake face during the cutting process, two chromel/ alumel thermocouples (K-type) of $0.25 \mathrm{~mm}$ diameter are used. The operating temperature is in the range of -100 to $1,100{ }^{\circ} \mathrm{C}$, and the time response is about $100 \mathrm{~ms}$. The Thermocouples calibration is carried using the linearization method. The thermocouples are embedded, thanks to a high conductive adhesive (AGAR SILVER), in $0.3 \mathrm{~mm}$ diameter holes, as shown in Fig. 4a, obtained by means of EDM (Electrical Discharge Machining). The location of the thermocouples in the insert is shown in Fig. $4 \mathrm{~b}$. The temperatures (TC1 and TC2) are directly recorded during the machining test with TWS software developed by Actarus ${ }^{\circledR}$ company in [39, 40], simultaneously with cutting force components recording.

\subsection{Experimental data}

From the machining test, cutting force components are measured, as reported in Table 3. For the cutting condition 
Fig. 2 a Insert TCMW16T304, b dimension characteristics $(\mathrm{L}=16.5 \mathrm{~mm}, \mathrm{D}=9.53 \mathrm{~mm}$, $\mathrm{D} 1=4.4 \mathrm{~mm}, \mathrm{~S}=3.97 \mathrm{~mm}$ ), and $\mathbf{c}$ SEM image of a polished surface inside the carbide (6 wt\% Co) tool [23] (a)

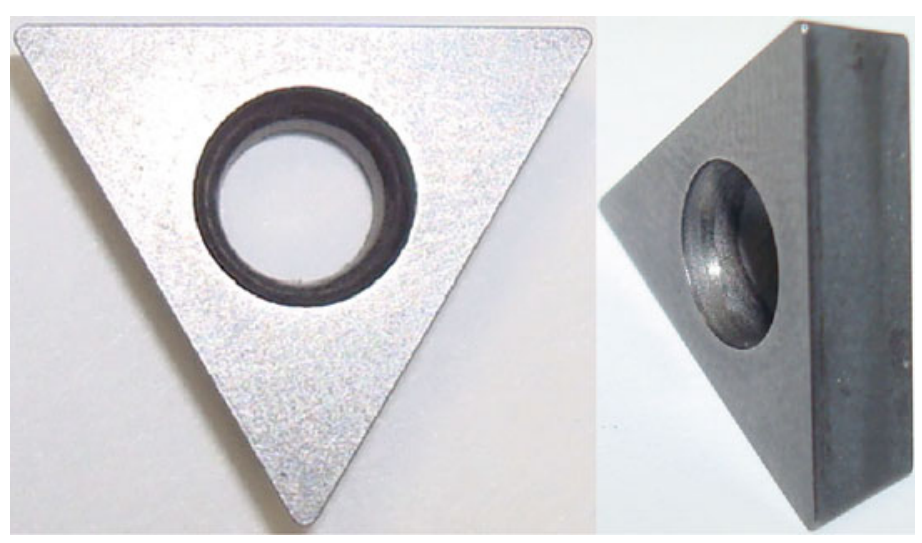

(b)

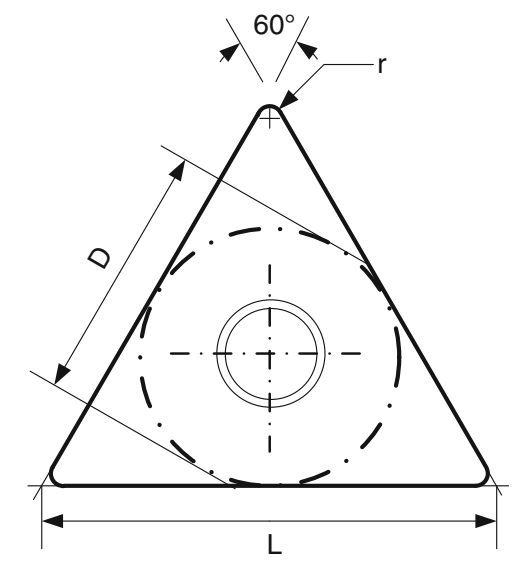

(c)

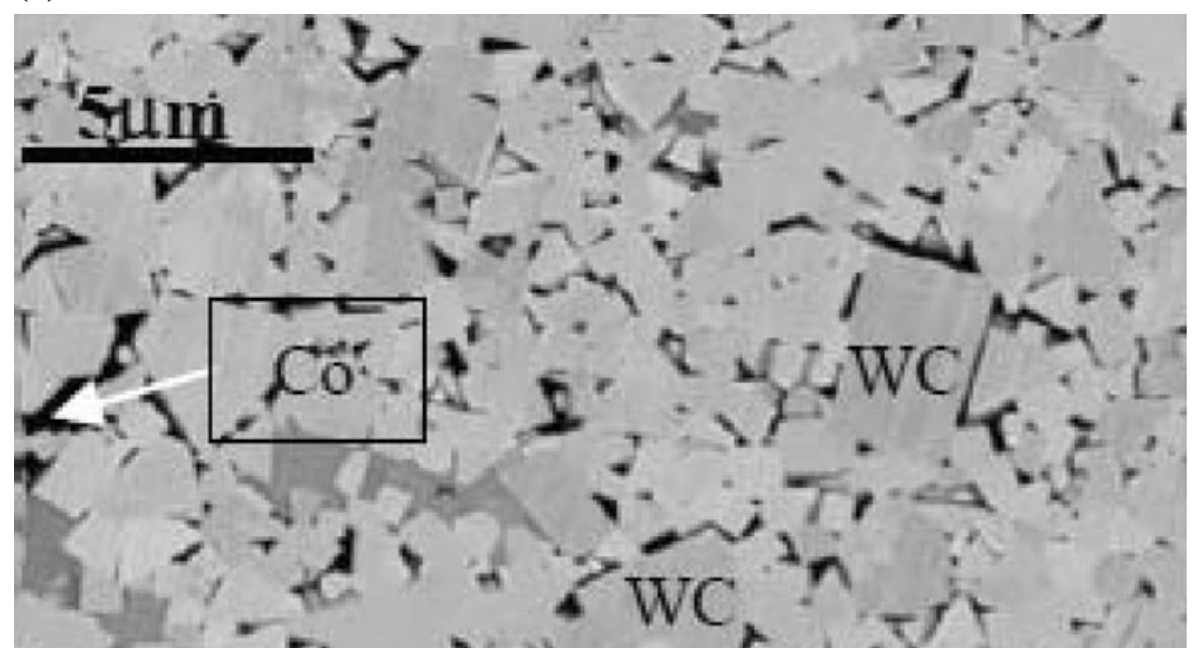

Table 1 Chemical composition (wt\%) of the WC-6Co [23]

\begin{tabular}{lllllllll}
\hline $\mathrm{C}$ & $\mathrm{Cr}$ & $\mathrm{Cu}$ & $\mathrm{Fe}$ & $\mathrm{Mg}$ & $\mathrm{Mn}$ & $\mathrm{Si}$ & $\mathrm{Ti}$ & $\mathrm{Zn}$ \\
\hline Balanced & Max. 0.1 & $3.8-4.9$ & Max. 0.5 & $1.2-1.8$ & $0.3-0.9$ & Max. 0.5 & Max. 0.15 & Max. 0.25 \\
\hline
\end{tabular}

used a continuous chip without segmentation is obtained, as shown in Fig. 5.

From the temperature measurement system, the temperature evolution is measured during machining, as shown in Fig. 6. High temperature level is obtained in TC1, as expected, since it is the closest to the tool-chip interface in the cutting configuration used here. After $5 \mathrm{~s}$ the cutting operation is stopped, so the temperature at thermocouples 


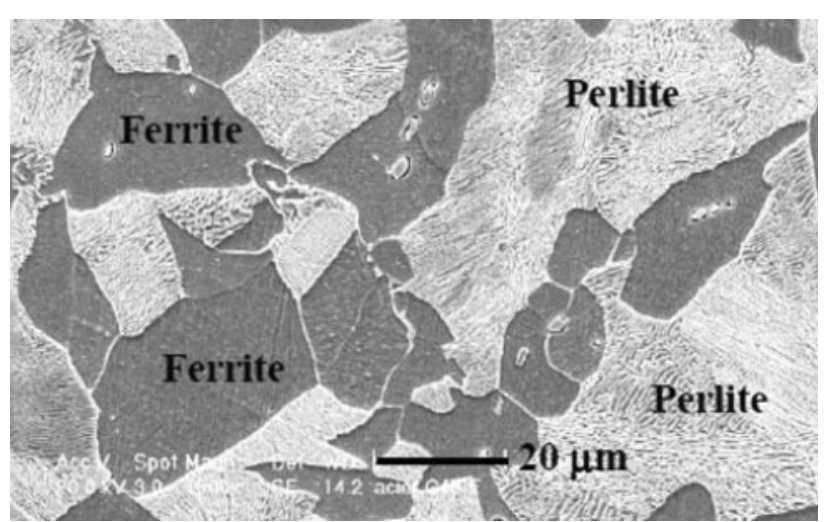

Fig. 3 Microstructure of the ferrite- perlite steel AISI 1045 [23]

decreases rapidly since there is no contact at the toolworkpiece interface (no heat generation by friction and plastic deformation responsible of the tool heating).

\section{Constitutive equations for modelling}

The modelling of the chip formation process is generally performed by considering the tool-workpiece couple. Only the vicinity of the cutting zone is considered in the numerical model. From the continuous media mechanics, each material point in the tool-workpiece couple should satisfy simultaneously (and at any time) the following mechanical and thermal balance equations:

$\operatorname{div} \sigma+f_{v}=\rho \ddot{u}$

$\lambda \nabla^{2} T-\rho c_{p} \dot{T}+\dot{q}_{v}=0$

where $\boldsymbol{\sigma}$ the Cauchy stress tensor, $\boldsymbol{f}_{v}$ the body force density vector, $\ddot{u}$ the acceleration vector, $T$ the temperature, $\rho$ the material density, $\lambda$ the thermal conductivity, $c_{p}$ the specific heat capacity, and $\dot{q}_{v}$ the volumetric heat generation.

The last balance equations are strongly coupled when they are applied to the tool-workpiece couple in machining, since the Cauchy stress tensor $\sigma$ depends on the temperature $T$ via the material behaviour laws (see the following section about constitutive model). Also in the thermal balance Eq. (2), volumetric heat generation $\dot{q}_{v}$ in the cutting zone is mainly due to the plastic work, so $T$ depends on $\sigma$ and plastic strain-rate. The different non-linearities (geometrical, behaviour and contact) make the analytical resolution of the two equilibrium Eqs. (1) and (2) practically impossible in practice, especially in three-dimensional configuration (oblique cutting), as considered in the (a)

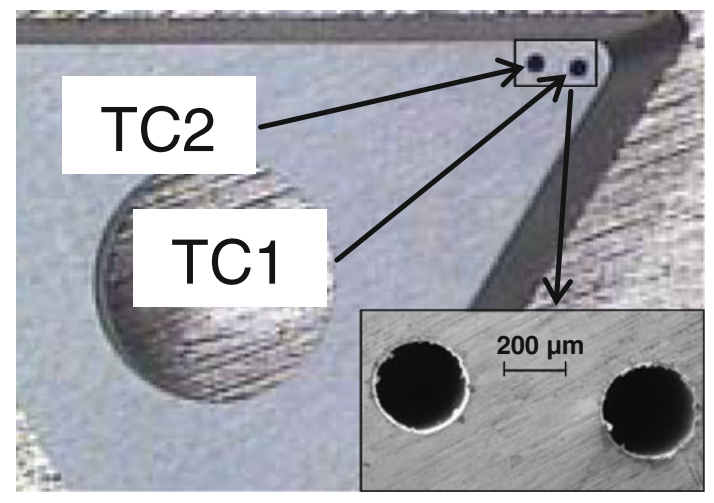

(b)

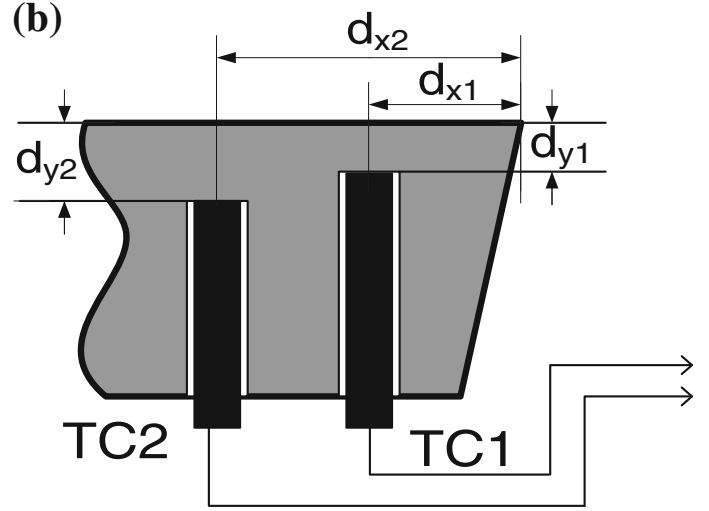

Fig. 4 a Insert with holes for thermocouples, and b location of the thermocouples (TC1: $\mathrm{d}_{\mathrm{x} 1}=1.6 \mathrm{~mm}, \mathrm{~d}_{\mathrm{y} 1}=0.5 \mathrm{~mm}, \quad \mathrm{TC} 2$ : $\left.\mathrm{d}_{\mathrm{x} 2}=2.4 \mathrm{~mm}, \mathrm{~d}_{\mathrm{y} 2}=1 \mathrm{~mm}\right)$

present work. A numerical approach, like the Finite Element Method (FEM), is generally necessary to solve this system of equations.

\subsection{Constitutive model}

To analyse the chip formation process, a Johnson-Cook model [45] has been used to represent the thermo-viscoplastic behaviour of the workmaterial, where the flow stress is given as follows:

$$
\begin{aligned}
& \bar{\sigma}=\underbrace{\left[A+B\left(\bar{\varepsilon}^{p}\right)^{n}\right]}_{\text {Hardening }} \underbrace{\left[1+C \ln \dot{\bar{\varepsilon}}^{*}\right]}_{\text {Viscosity }} \underbrace{\left[1-T^{* m}\right]}_{\text {Softening }} \\
& \text { with } \quad \dot{\bar{\varepsilon}}^{*}=\frac{\dot{\bar{\varepsilon}}^{p}}{\dot{\bar{\varepsilon}}_{0}} \text { and } T^{*}=\frac{T-T_{0}}{T_{m}-T_{0}}
\end{aligned}
$$

where $A, B, C, m$ and $n$ are the material parameters, $\bar{\varepsilon}^{p}$ the von Mises equivalent plastic strain, $\dot{\bar{\varepsilon}}^{p}$ the von Mises equivalent plastic strain rate, $\dot{\bar{\varepsilon}}_{0}$ the reference equivalent
Table 2 Chemical composition (wt\%) of the AISI 1045 steel [23]

\begin{tabular}{lllllllll}
\hline $\mathrm{C}$ & $\mathrm{Si}$ & $\mathrm{Mn}$ & $\mathrm{P}$ & $\mathrm{S}$ & $\mathrm{Cr}$ & $\mathrm{Ni}$ & $\mathrm{Mo}$ & $\mathrm{Cu}$ \\
\hline 0.45 & 0.22 & 0.66 & 0.027 & 0.032 & 0.26 & 0.15 & 0.02 & 0.18 \\
\hline
\end{tabular}


Table 3 Average cutting force components and resultant force for the cutting condition: $V_{c}=250 \mathrm{~m} / \mathrm{min}, f=0.1 \mathrm{~mm}$, ap $=1.1 \mathrm{~mm}$

\begin{tabular}{llll}
\hline $\begin{array}{l}\text { Resultant cutting force, } \\
F_{R}(\mathrm{~N})\end{array}$ & $\begin{array}{l}\text { Cutting (tangential) force, } \\
F_{c}(\mathrm{~N})\end{array}$ & $\begin{array}{l}\text { Depth (radial) force, } F_{p} \\
(\mathrm{~N})\end{array}$ & $\begin{array}{l}\text { Feed (axial) force, } F_{f} \\
(\mathrm{~N})\end{array}$ \\
\hline 493 & 366 & 102 & 314 \\
\hline
\end{tabular}

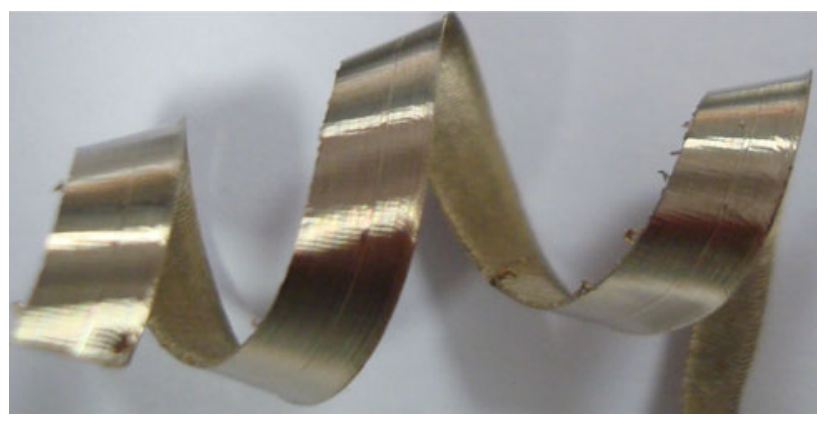

Fig. 5 Experimental chip morphology: continuous chip without segmentation

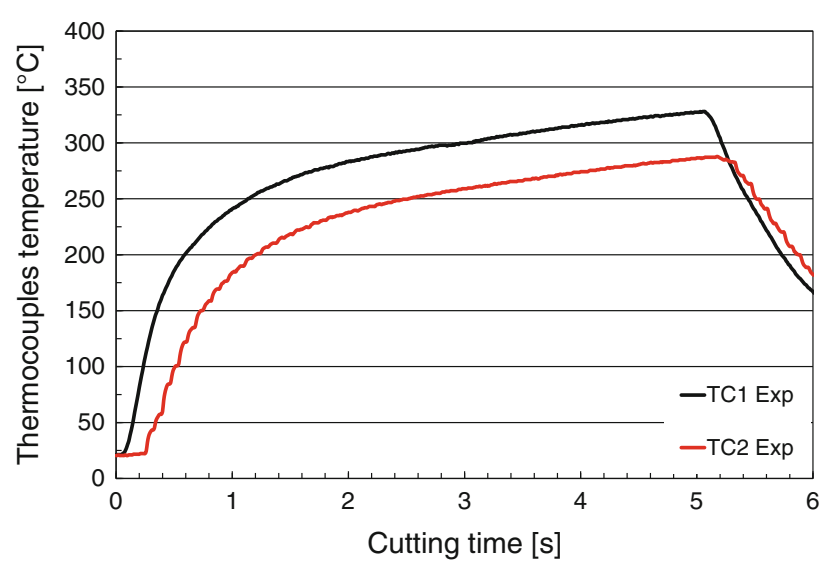

Fig. 6 Temperature evolution at thermocouples TC1 and TC2 during machining; after $5 \mathrm{~s}$ cutting is stopped

plastic strain rate, $T_{m}$ and $T_{0}$ are, respectively, the material melting temperature and the reference ambient temperature.

As the mechanical behaviour is affected by temperature (softening effect), the mechanical plastic work generates heat flux which result in temperature rise. The heat generation due to this phenomenon is described by the following relationship:

$\dot{q}_{p}=\eta_{p} \bar{\sigma}: \dot{\bar{\varepsilon}}^{p}$

where $\eta_{p}$ is the plastic work conversion factor (TaylorQuinney factor).

\subsection{Interface behaviour}

The contact behaviour of the tool-workpiece interface is defined by the relationship between the normal friction stress $\sigma_{n}$ and the shear friction stress $\tau_{f}$, as follows: $\tau_{f}=\left\{\begin{array}{lll}\mu \sigma_{n} & \text { if } & \mu \sigma_{n}<\tau_{\mathrm{Max}} \\ \tau_{\mathrm{Max}} & \text { if } & \mu \sigma_{n} \geq \tau_{\mathrm{Max}}\end{array}\right.$

where $\mu$ is the friction coefficient and $\tau_{\max }$ is the shear stress limit, considered equal to the initial plastic flow shear stress of the workmaterial (AISI 1045 steel), since its ductility is much lower compared to that of the cutting tool (cemented tungsten carbide WC-6Co).

The friction process at the tool-workpiece interface generates a heat which can be evaluated by the following relation:

$\dot{q}_{f}=\eta_{f} \tau_{f} \dot{\gamma}$

where $\dot{\gamma}$ is the relative sliding velocity, $\tau_{f}$ the friction stress given by Eq. (5), $\eta_{f}$ the frictional work conversion factor. By assuming that all the frictional work is converted into heat, $\eta_{f}=1$ is often considered.

The mechanical plastic work of the chip affects heat exchange at the tool-workpiece interface. To take into account this energy in the heating of the tool, the heat conduction flux $\dot{q}_{c}$ is introduced, so the heat balance at the interface can finally be written as follows:

$$
\begin{aligned}
& \dot{q}_{\rightarrow \text { tool }}=f_{f} \dot{q}_{f}+\dot{q}_{c} \\
& \dot{q}_{\rightarrow \text { workpiece }}=\left(1-f_{f}\right) \dot{q}_{f}-\dot{q}_{c} \\
& \text { with } \\
& \dot{q}_{c}=h\left(T_{\text {int }-w}-T_{\text {int-t }}\right)
\end{aligned}
$$

where $\dot{q}_{\rightarrow \text { tool }}$ is the heat flux transmitted to the tool, $\dot{q}_{\rightarrow \text { workpiece }}$ is the heat flux going into the workpiece (calorific energy mainly evacuated by the chip), $f_{f}$ is the fraction of the friction energy conducted into the tool (heat partition coefficient), $h$ is the interface heat transfer coefficient, while $T_{\text {int-w }}$ and $T_{\text {int- } t}$ are temperatures, respectively, of workpiece and tool at the tool-workpiece interface.

\section{Two-steps finite element modelling}

\subsection{Motivation}

The challenge in numerical modelling of machining processes is to obtain the main physical quantities characterising the process in reasonable computational time with acceptable accuracy. In order to analyse the chip formation process in a non-orthogonal cutting configuration (oblique cutting), a FEM is widely used, since it allows treating the 
problem in 3D case with fewer simplifying assumptions, unlike analytical approaches. However, one of the major inconvenient of the FEM is the high CPU time necessary to obtain all quantities. In fact, simulation of the chip formation process in $3 \mathrm{D}$ case over few milliseconds of the cutting time, as it can be confirmed in Sect. 5.1, necessitates few days of CPU time to obtain stabilized cutting force, chip morphology and its flow direction. But heat diffusion into the cutting tool necessitates calculation over few seconds of the cutting time; see Fig. $6 b$ for the temperature evolution at the thermocouples. Clearly, it is not possible to obtain with the same FE calculation and in reasonable CPU time all thermomechanical quantities characterising the process.

As illustrated in Table 4, new idea is developed which consists to decompose the problem on two successive calculations (two-steps FE-based modelling):

- The first one is a fully 3D thermomechanical modelling of the chip formation process; which allows estimating all components of the cutting force, chip morphology as well as the chip flow direction, and other quantities necessary for the second-step of calculation.

- The second one is a fully 3D thermal modelling of the heat transfer into the cutting tool, using some quantities obtained at the first-step of calculation, like tool-chip interface pressure, sliding velocity distributions as well as contact area.

In order to illustrate the robustness of the proposed approach, a comparison between experimental data (cutting force components, chip morphology) and temperature measured by the two thermocouples, embedded in the tool close to the active zone of the cutting face, is performed in Sect. 5.2.

\subsection{First step: modelling of the chip formation process}

The 3D FE model, defined for the first step calculation, is shown in Fig. 7. The FE model for turning process consists to position the insert against the machined material zone, representing the workpiece; which is affected by the cutting process. Only a part of the insert is considered, as highlighted in Fig. 7a, including the cutting face and thermocouple holes. The cutting configuration, as shown in Fig. 7b, corresponds to the experimental one (see Fig. 1a).

Physical and thermal boundary conditions are defined. In the model, the workpiece is fixed at the bottom and lateral faces and cutting velocity is applied to the cutting tool, as shown in Fig. 7b. While thermal boundary conditions take into account heat exchange with environment for all surfaces of the insert and workpiece, except at the toolworkpiece interface where equations listed in Sect. 3.2 are considered. The initial temperature for the tool-workpiece couple is taken equal to $20{ }^{\circ} \mathrm{C}$.

The workpiece and tool are meshed with tetrahedron finite element of Deform code [37], a coupled linear displacement-temperature 4 nodes element, with about 290,000 elements for the insert and 156,000 elements for the workpiece. The initial mesh of the tool-workpiece couple and the mesh refinement of the cutting zone are

Table 4 Illustration of the two-steps finite element modelling strategy

Chip formation process
$\begin{aligned} & \text { Simulation over a short cutting time } \\ & \text { (few milliseconds): } \\ & \text { Stabilized cutting force } \\ & \text { Stabilized chip morphology } \\ & \text { Chip flow direction }\end{aligned} \begin{aligned} & \text { Data for second step: } \\ & \text { Tool-chip contact area } \\ & \text { Contact pressure distribution } \\ & \text { Sliding velocity }\end{aligned}$
$\begin{aligned} & \text { Heat flux and temperature fields } \\ & \text { Temperature at the thermocouples }\end{aligned}$



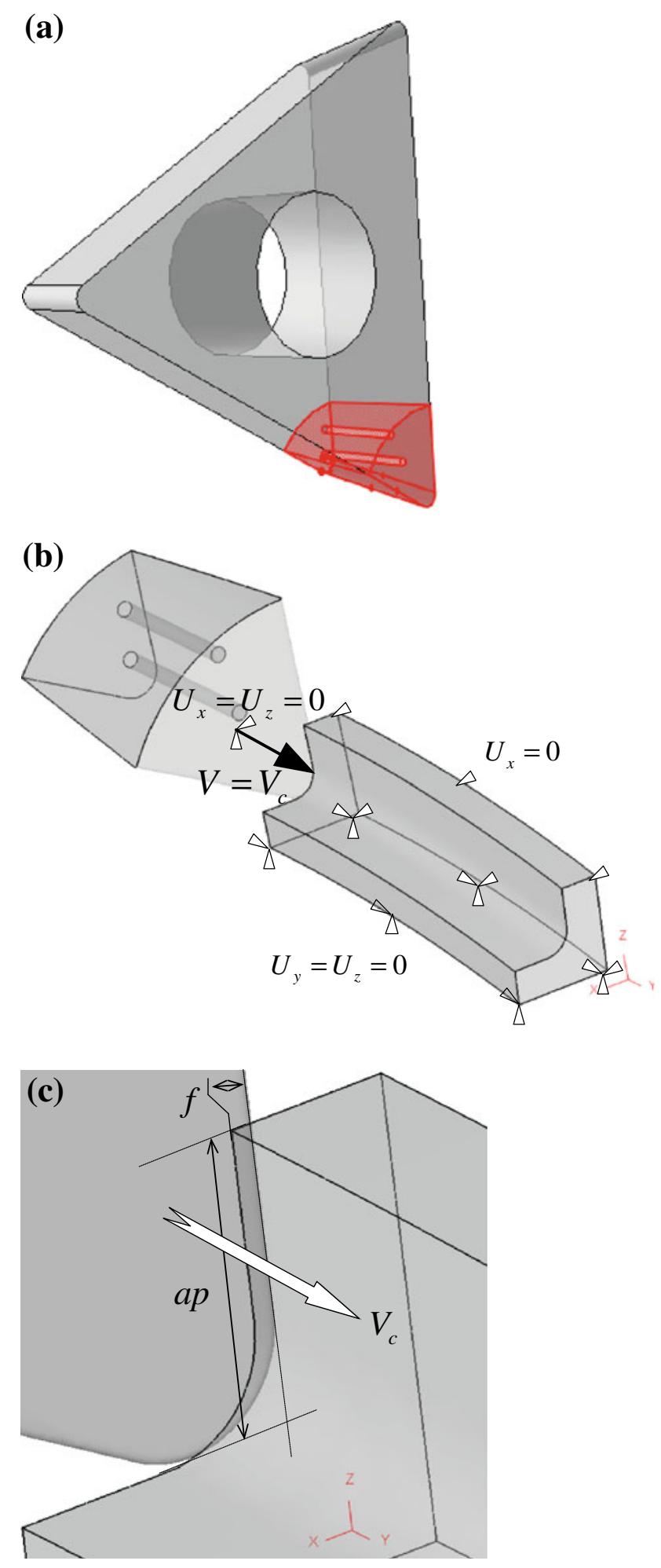

Fig. 7 First-step FE model for the simulation of the chip formation process [37]: a highlighting of the considered part of the cutting tool, b initial tool-workpiece configuration with boundary conditions and c highlighting of the cutting zone

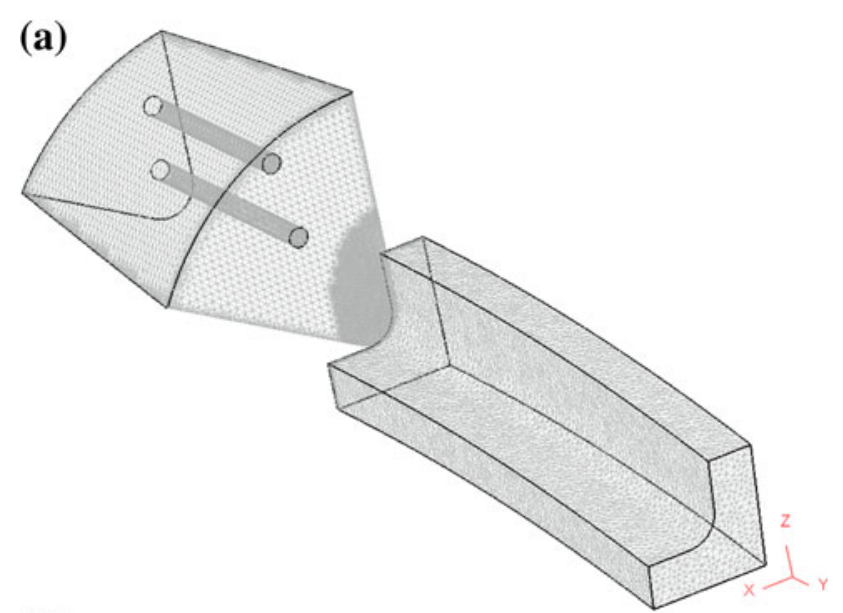

(b)

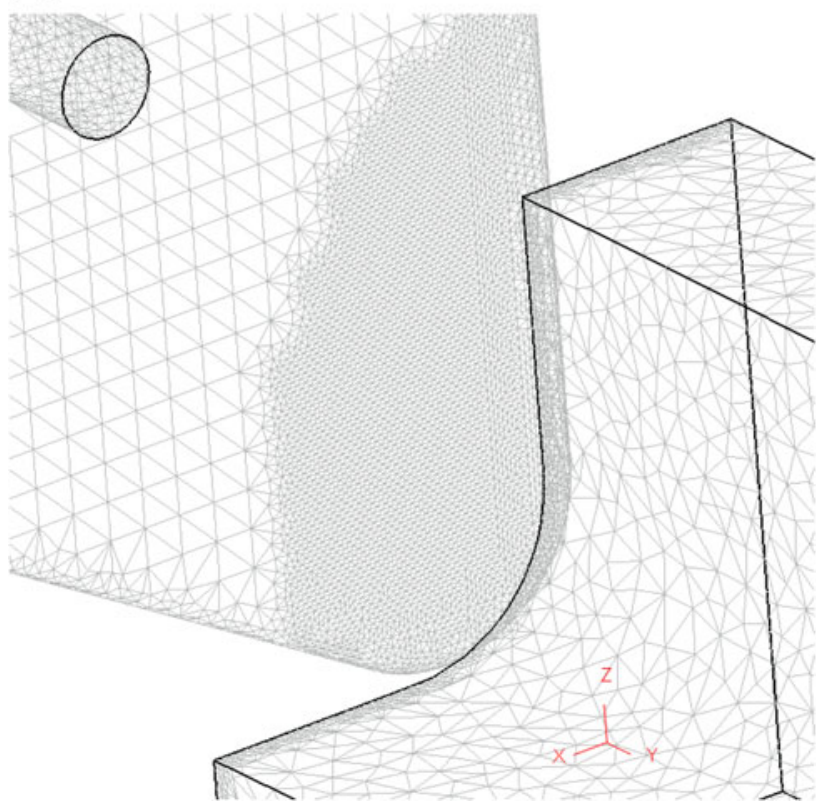

Fig. 8 Mesh of the tool-workpiece couple, with mesh refinement of the cutting zone [37]: a initial tool-workpiece mesh and b highlighting the mesh refinement of the cutting zone

shown in Fig. 8a and b respectively. A minimum element size (about $10 \mu \mathrm{m}$ ) is taken in the insert (at the active cutting face) and chip zones. This value is chosen after some numerical tests to find a good compromise between result accuracy and reasonable CPU time.

\subsection{Second step: modelling of the heat transfer} into the insert

The second step consists to model the heat transfer into the cutting tool. The insert is represented in totality unlike in the first-step calculation, where only the active part of the 
(a)

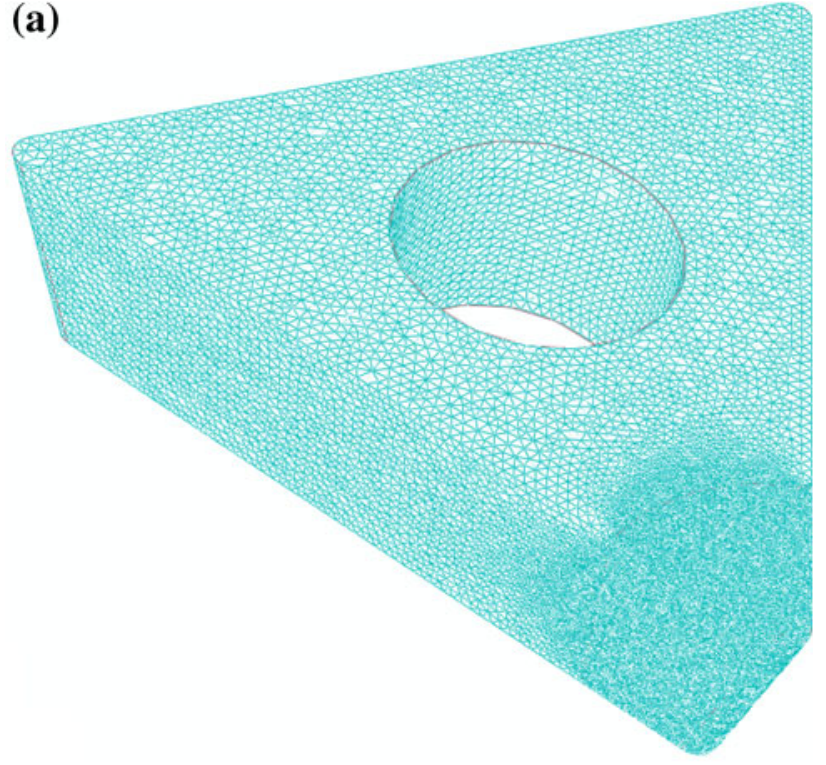

(b)

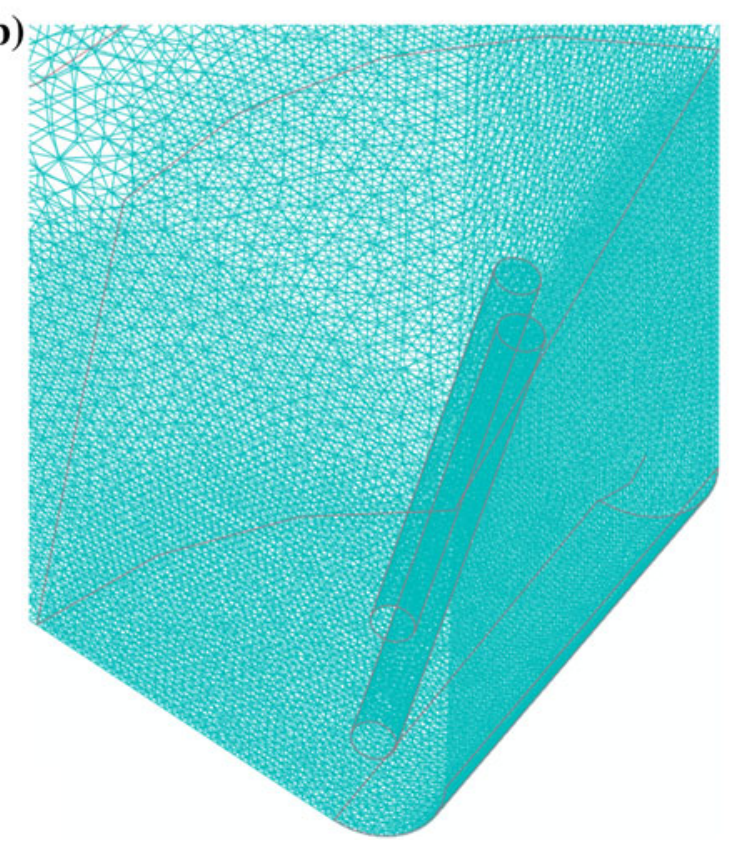

Fig. 9 Mesh of the insert, with mesh refinement of the cutting zone [38]: a mesh of the cutting tool and b highlighting the mesh refinement of the cutting zone

insert is considered. In order to compare to experimental temperature, holes machined in the insert to introduce thermocouples are also considered in the model. Figure 9 shows the mesh of the insert with DC3D4 FE of Abaqus library, a 4 nodes linear heat transfer tetrahedron element (more than 390,000 elements).

To represent the real heat diffusion into the insert, adequate thermal boundary conditions should be considered. The temperature measured by the two thermocouples will be used to validate the heat diffusion model. As shown (a)

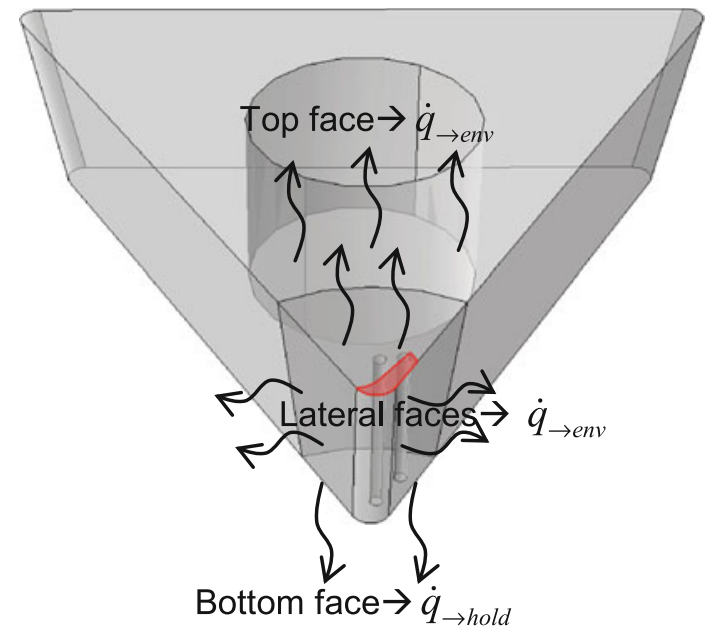

(b)

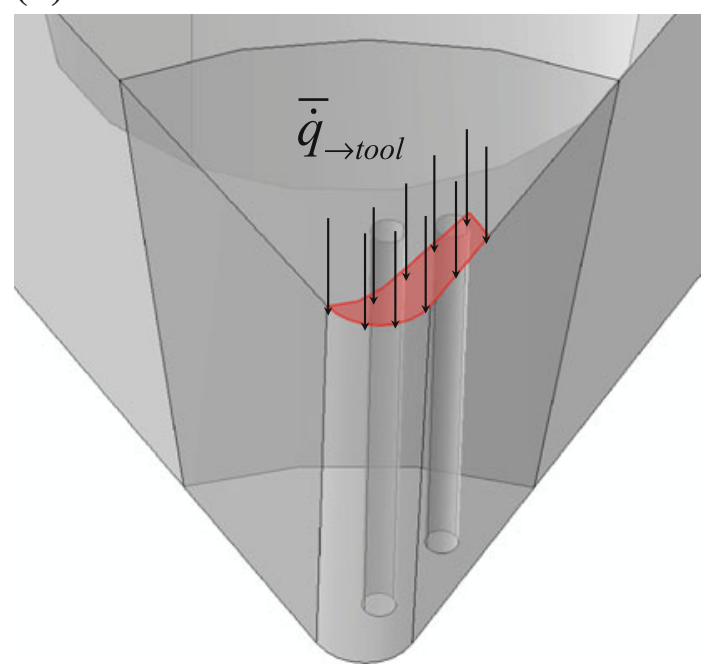

(c)

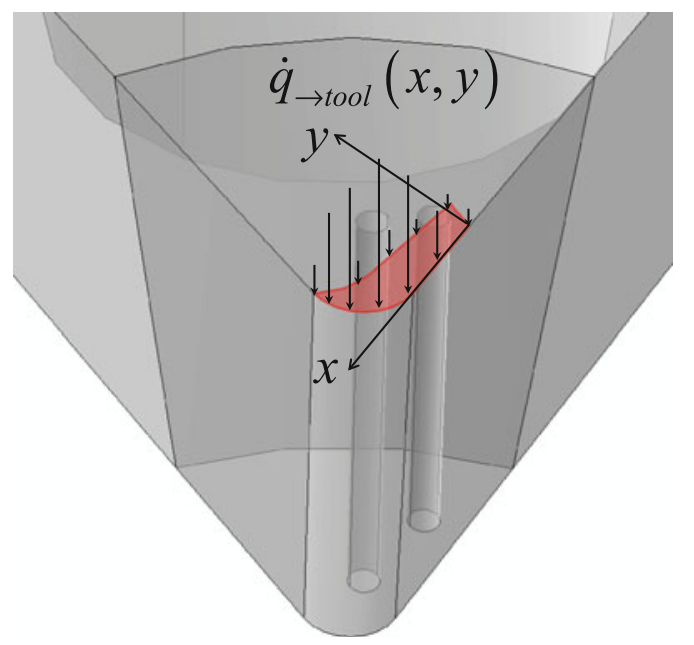

Fig. 10 Thermal boundary conditions: a heat exchange with environment and toolholder, $\mathbf{b}$ applied uniform and $\mathbf{c}$ non-uniform heat flux at the tool-chip contact face 
Table 5 Basic mechanical and thermal properties of workpiece and tool [23]

\begin{tabular}{lll}
\hline $\begin{array}{l}\text { Physical } \\
\text { parameter }\end{array}$ & $\begin{array}{l}\text { Workpiece } \\
\text { (AISI 1045) }\end{array}$ & $\begin{array}{l}\text { Tool } \\
(\mathrm{WC}-\mathrm{Co})\end{array}$ \\
\hline$\rho\left(\mathrm{kg} / \mathrm{m}^{3}\right)$ & 8,000 & 14,900 \\
$E(\mathrm{MPa})$ & $210.10^{3}$ & 600 \\
$v$ & 0.33 & 0.22 \\
$c_{p}\left(\mathrm{~J} / \mathrm{kg} /{ }^{\circ} \mathrm{C}\right)$ & $c_{p}=0.504 \mathrm{~T}+420$ & 222 \\
$\lambda\left(\mathrm{W} / \mathrm{m} /{ }^{\circ} \mathrm{C}\right)$ & $\lambda=-0.0281 T$ & $20 \leq \mathrm{T} \leq 300:$ \\
& +52.61 & $\lambda=-0.1131 \mathrm{~T}+120.03$ \\
& & $300 \leq \mathrm{T} \leq 500:$ \\
& & $\lambda=-0.005 \mathrm{~T}+87.5$ \\
& & $500 \leq \mathrm{T} \leq 600:$ \\
$\alpha\left(\mathrm{m} / \mathrm{m} /{ }^{\circ} \mathrm{C}\right)$ & $12.10^{-6}$ & $\lambda=-0.02 \mathrm{~T}+95$ \\
$\eta p$ & 0.9 & $\times$ \\
$T_{m}\left({ }^{\circ} \mathrm{C}\right)$ & 1,460 & $\times$ \\
$T_{0}\left({ }^{\circ} \mathrm{C}\right)$ & 20 & $\times$ \\
\hline
\end{tabular}

in Fig. 10 three types of boundary conditions are applied to the insert:

1. heat exchange with environment (top and lateral faces), see Fig. 10a:

$\dot{q}_{\rightarrow \text { env }}=h_{\text {env-tool }}\left(T_{\text {env }}-T_{\text {tool }}\right)$

2. heat exchange with the tool holder (bottom face), see Fig. 10a:

$\dot{q}_{\rightarrow \text { hold }}=h_{\text {hold-tool }}\left(T_{\text {hold }}-T_{\text {tool }}\right)$

3. applied heat flux at the tool-chip contact face, see Fig. $10 \mathrm{~b}$ and c. Here, only the heat due to the friction is considered, and two cases are defined:

i. the first one corresponds to apply a uniform heat flux, see Fig. 10b:

$\overline{\dot{q}}_{\rightarrow t o o l}=f_{f} \cdot \dot{q}_{f}=f_{f} \cdot \eta_{f} \cdot \bar{\tau}_{f} \cdot \overline{\dot{\gamma}}$

where $\bar{\tau}_{f}$ and $\overline{\dot{\gamma}}$ are, respectively the average values of sliding stress and sliding velocity at the tool-chip interface, computed from the first-step model (chip formation process).

ii. the second one corresponds to apply a nonuniform heat flux, see Fig. 10c, by taking into account the non-uniform contact pressure distribution at the tool-chip interface, which is obtained from the first-step model, so:

$\dot{q}_{\rightarrow \text { tool }}(x, y)=f_{f} \cdot \dot{q}_{f}=f_{f} \cdot \eta_{f} \cdot \tau_{f}(x, y) \cdot \dot{\gamma}(x, y)$

where $\tau_{f(x, y)}$ and $\dot{\gamma}(x, y)$ are local values of the sliding stress and sliding velocity at the tool-chip contact face, respectively, computed from the first-step model.

From the thermal boundary conditions, two cases are defined to analyse heat diffusion into the insert: applied
Table 6 Johnson-Cook thermo-visco-plastic parameters of workpiece-first-step model [46]

\begin{tabular}{lllll}
\hline$A(\mathrm{MPa})$ & $B(\mathrm{MPa})$ & $n$ & $C$ & $m$ \\
\hline 553.1 & 600.8 & 0.234 & 0.0134 & 1 \\
\hline
\end{tabular}

Table 7 Workpiece-tool interface parameters-first-step model $[23,37]$

\begin{tabular}{llll}
\hline$\mu$ & $\tau_{\max }(\mathrm{MPa})$ & $h\left(\mathrm{~W} / \mathrm{m}^{2} /{ }^{\circ} \mathrm{C}\right)$ & $f_{f}$ \\
\hline 0.6 & No limit & $45.10^{3}$ & 0.1 \\
\hline
\end{tabular}

Table 8 Heat transfer parameters-second-step model [23, 37]

\begin{tabular}{lllll}
\hline$T_{\text {env }}\left({ }^{\circ} \mathrm{C}\right)$ & $\begin{array}{l}T_{\text {hold }} \\
\left({ }^{\circ} \mathrm{C}\right)\end{array}$ & $\begin{array}{l}h_{\text {env-tool }} \\
\left(\mathrm{W} / \mathrm{m}^{2} /{ }^{\circ} \mathrm{C}\right)\end{array}$ & $\begin{array}{l}h_{\text {hold-tool }} \\
\left(\mathrm{W} / \mathrm{m}^{2} /{ }^{\circ} \mathrm{C}\right)\end{array}$ & $f_{f}$ \\
\hline 20 & 20 & 90 & $5.10^{3}$ & 0.13 \\
\hline
\end{tabular}

uniform and non-uniform heat flux at the tool-chip contact face. The comparison between the two cases with respect to measured temperature by thermocouples will be given in Sect. 5.2.

\subsection{Material and interface parameters}

Basic physical properties of the workpiece and tool materials are given in Table 5, and behaviour parameters of the workpiece material are given in Table 6 . The parameters of the tool-workpiece interface model are given in Table 7 , while the heat transfer parameters involved in the secondstep model are given in Table 8 .

\section{Results and discussion}

As described in Sects. 4.2 and 4.3, from each step of calculation some pertinent results can be obtained. Here, these results are discussed in terms of the chip formation process (cutting force, chip morphology and chip flow direction) and heat transfer into the cutting tool, with comparison with experimental results, given in Sect. 2.2.

\subsection{Analysis of the chip formation process}

From the first-step FE model the chip formation process is analysed. Chip morphology exhibits the signature of the correct behaviour taken in the simulation. So Fig. 11 illustrates the chip morphology obtained from the numerical simulation. The continuous chip is well reproduced as in experiment as well as its flow direction.

As shown in Fig. 12, predicted cutting force components $\left(F_{c}, F_{f}\right.$ and $\left.F_{p}\right)$ and resultant $\left(F_{R}\right)$ indicate that there 
Fig. 11 Simulated continuous chip and its flow direction: comparison with the experimental chip
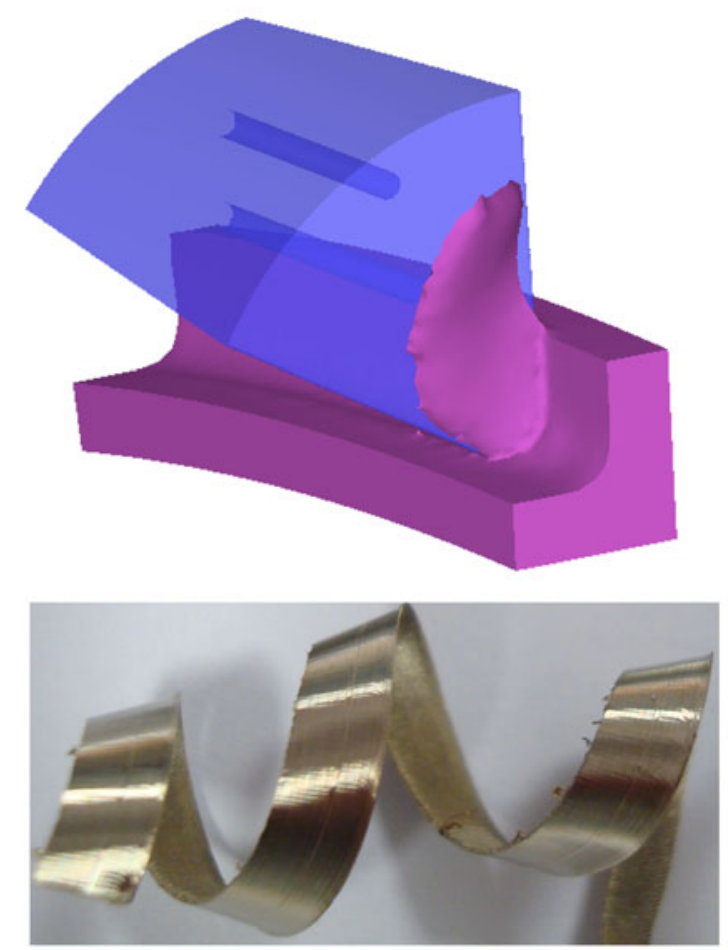
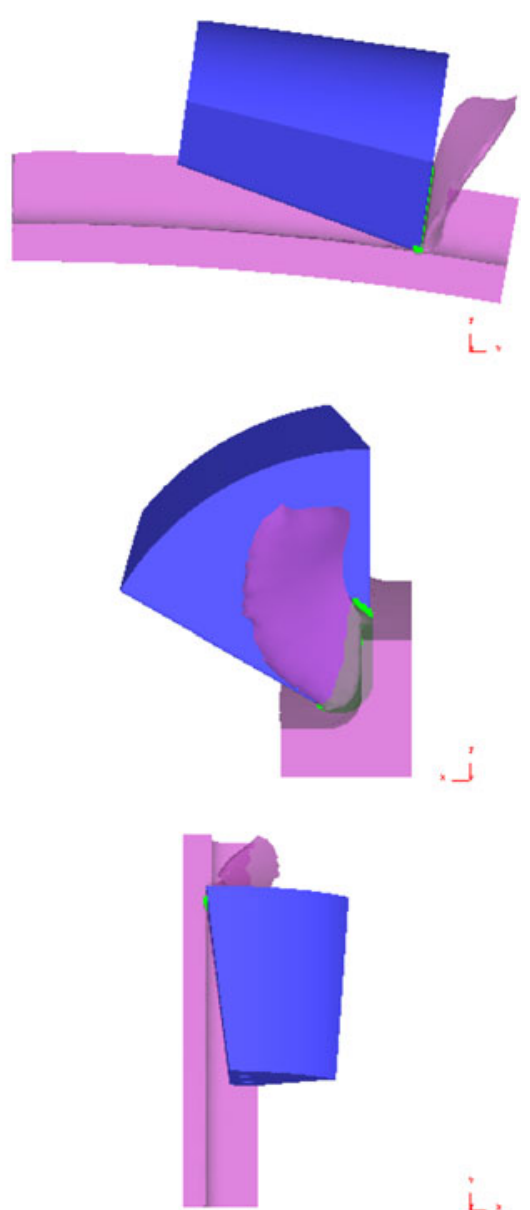

are some differences with experimental ones. In fact, the feed force is underestimated by calculation, since in the numerical model a circular movement is applied to the insert, while in real machining process helical movement occurs. This means that a reaction force in feed direction, in reality, is due at the same time to the permanent movement of the insert in the feed direction and the chip formation. In the numerical model, this axial movement is not taken correctly (the insert is positioned in fixed feed and circular movement is applied), so the feed reaction force is due only to the chip formation. While the depth reaction force is well reproduced, since the kinematics in the radial direction is well taken by the numerical model (there is no movement in the radial direction during the chip formation process as in real configuration of machining). As reported in Table 9, globally the average cutting force components and resultant are comparable to the experimental ones. From the performed simulation, contact pressure distribution at the active zone of the insert is also estimated, as shown in Fig. 13.

To perform this first-step calculation in Deform FE software, with optimal mesh resolution (more than 446,000 elements for the tool-workpiece couple), 8 days are necessary. It was shown that temperatures given by thermocouples

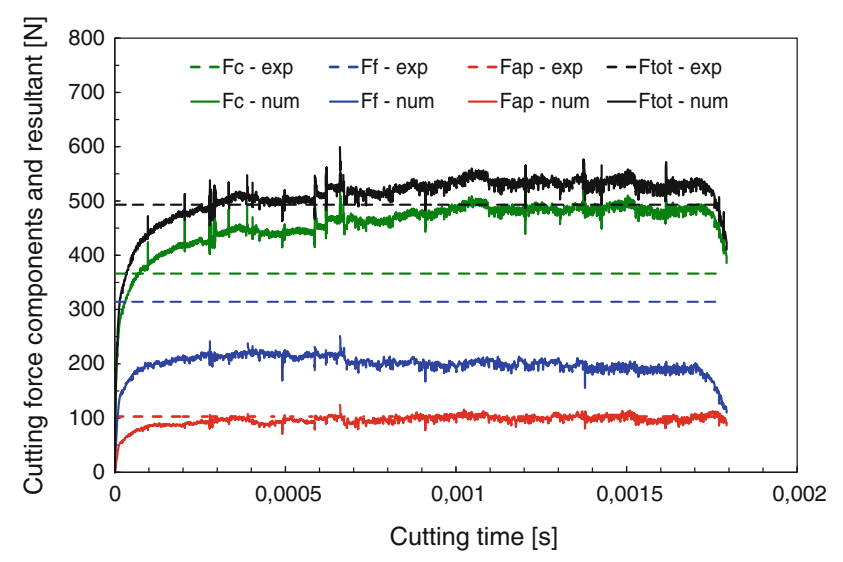

Fig. 12 Experimental versus numerical cutting force components and resultant

Table 9 Comparison between experimental and numerical values of average cutting force components and the resultant force

\begin{tabular}{lll}
\hline Force $(\mathrm{N})$ & Experiment & Numerical \\
\hline$F_{c}$ & 366 & 480 \\
$F_{f}$ & 314 & 205 \\
$F_{p}$ & 102 & 104 \\
$F_{R}$ & 493 & 532 \\
\hline
\end{tabular}



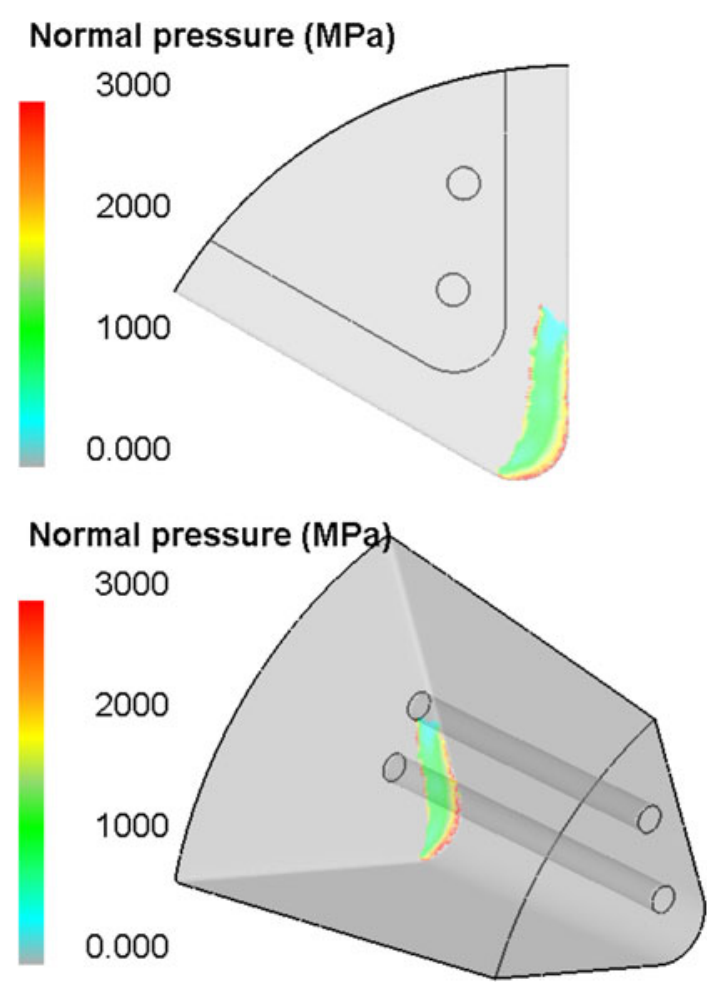

Fig. 13 Contact pressure distribution at the active face of the insert obtained from the first-step FE calculation

\section{Temperature (C)}
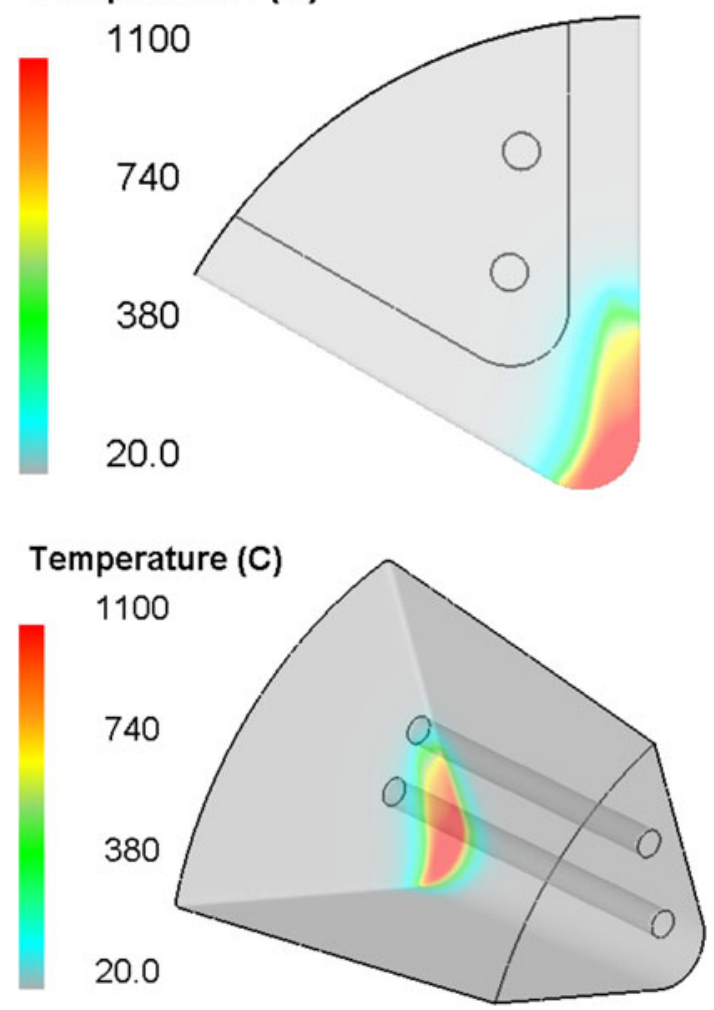

Fig. 14 Temperature distribution in the insert obtained from the first-step FE calculation: thermocouples are not affected (a)

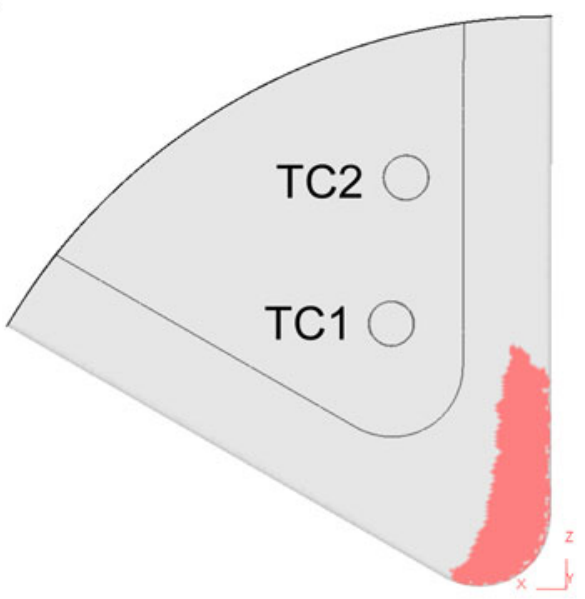

(b)

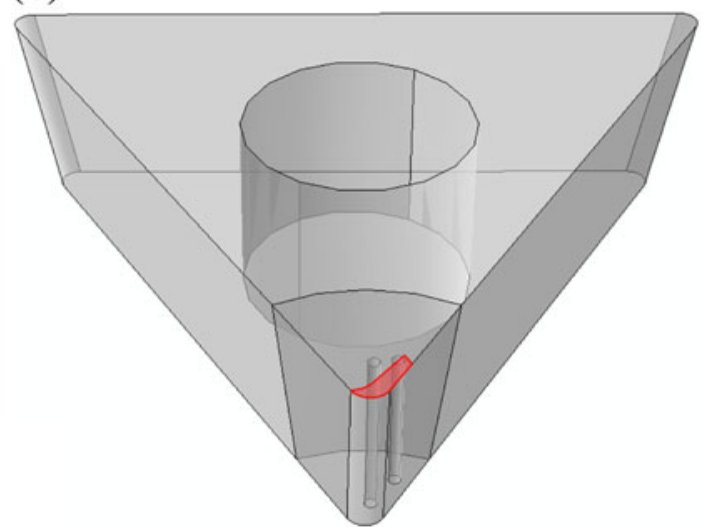

Fig. 15 a Contact area obtained from the first-step FE model, and b reproduced at the active zone of the insert for the heat diffusion analysis with the second-step model

stay at the initial value of $20{ }^{\circ} \mathrm{C}$ (see Fig. 14), so no significant heat diffusion occurs during the cutting duration (about $1.8 \mathrm{~ms})$. This implies that it is not possible to obtain the temperature evolution in the bulk of the insert and at the thermocouples with reasonable CPU time. However, using some quantities obtained from this first-step calculation and additional adequate thermal boundary conditions, as described in Sect. 4.3, allows simulating heat diffusion into the insert over a few seconds in reasonable CPU time. Indeed, simulation of the heat transfer into the tool by solving only the heat balance Eq. (2) by EF takes much less computing time compared to solving the problem dealt with the first thermomechanical model, where mechanical and thermal balance Eqs. (1) and (2) are strongly coupled.

5.2 Analysis of the heat transfer into the cutting tool

The two cases of the heat diffusion into the insert defined in Sect. 4.3, which correspond to applied uniform and 
(a)

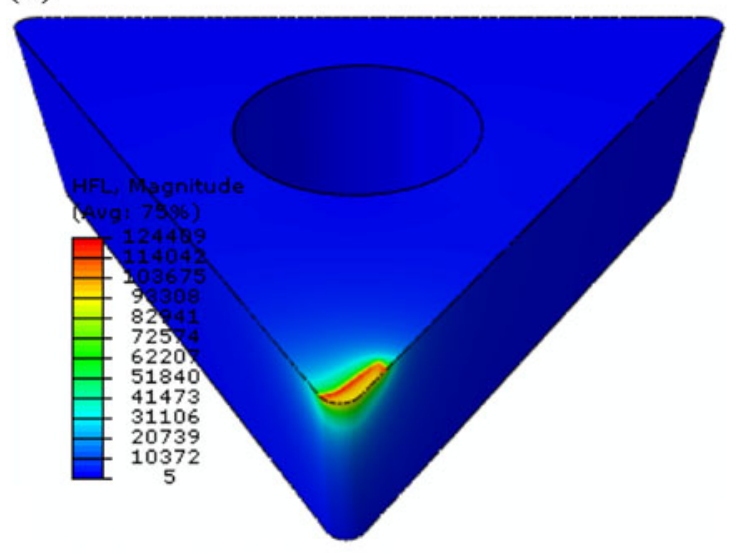

(c)

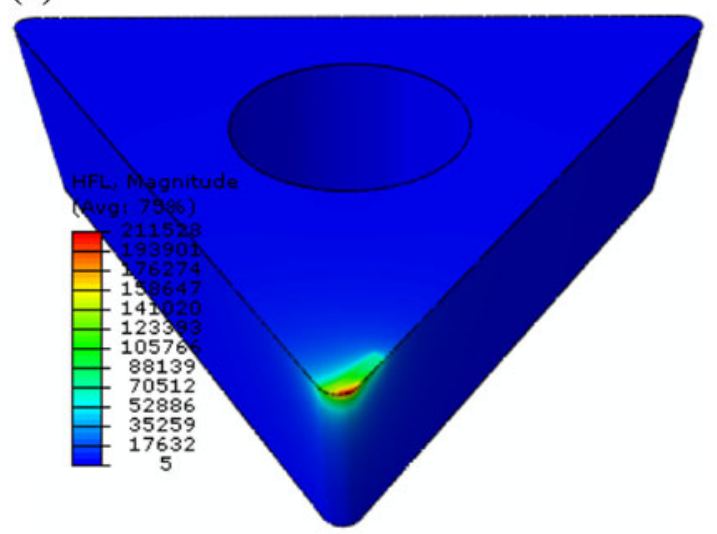

(b)

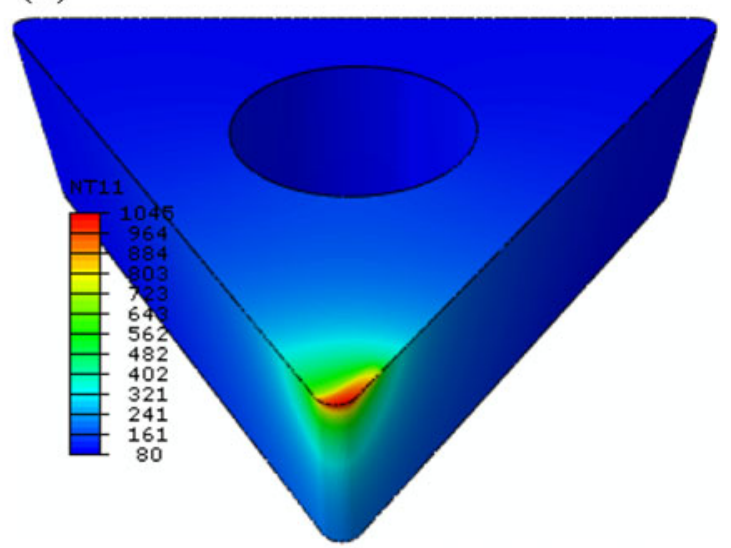

(d)

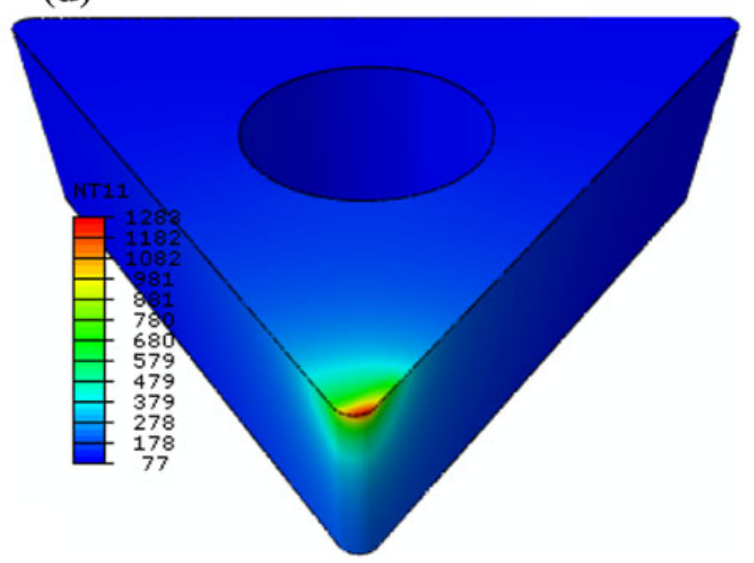

Fig. 16 Heat flux and temperature distributions in the insert at cutting time equal $5 \mathrm{~s}$ : $\mathbf{a}$ heat flux and $\mathbf{b}$ temperature fields for applied uniform heat flux, $\mathbf{c}$ heat flux and $\mathbf{d}$ temperature fields for applied non-uniform heat flux

non-uniform heat fluxes at the tool area in contact with the chip, are analysed here. To perform such simulations, contact pressure and sliding velocity distributions as well as contact area are extracted from the first-step calculation. As shown in Fig. 15, the geometry of the contact area (Fig. 15a) is reproduced in the insert (Fig. 15b) to apply the tool-chip heat flux.

From the performed heat diffusion simulations, the heat flux and temperature distributions in the insert at any time are obtained, Fig. 16. The heat flux and temperature fields are clearly affected by the applied heat flux. For the applied non-uniform, heat flux temperature is highly localized at the cutting edge (in the sticking region), while for applied uniform heat flux temperature is quasi-uniform at the contact face.

The comparison between measured and numerical temperature evolution at the thermocouples is given in Fig. 17. It can be observed from Fig. 17a that the applied uniform heat flux fails to fit the measured temperatures at the two thermocouples. On the other hand in Fig. 17b, the applied non-uniform heat flux, which better corresponds to the actual heat exchange at the tool-chip interface in machining, gives the best result, especially for the temperature evolution on the thermocouple TC1. However in these two cases, the temperature evolution on the thermocouple TC2 is poorly reproduced (underestimated). This is due to the underestimation of the contact area in the firststep calculation. As shown in Fig. 15, the thermocouple TC1 is closer to the contact face than the thermocouple TC2, so temperature at the TC2 will be more affected by the error on the estimation of this contact area and its shape.

\section{Conclusions}

To analyse the heat diffusion in complex machining operation, a new approach based on two steps of 3D FE modelling has been developed. The proposed strategy uses tool-chip interface parameters such as contact pressure, 
(a)

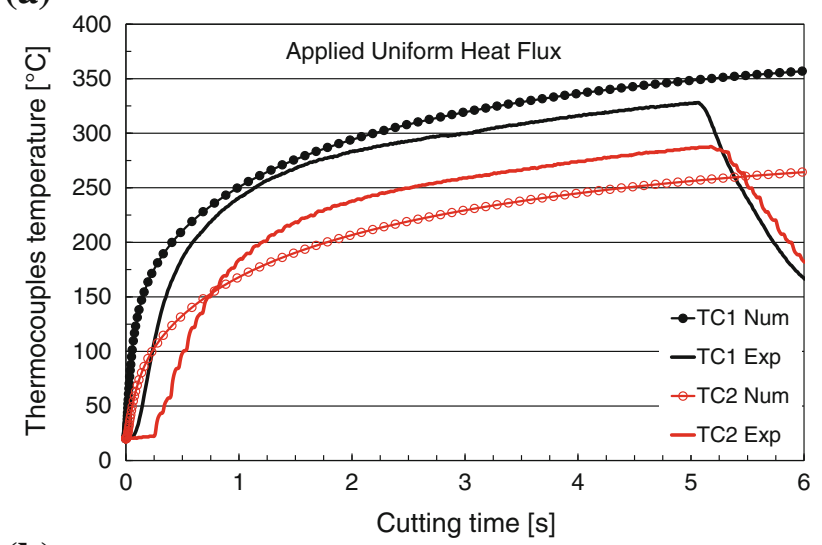

(b)

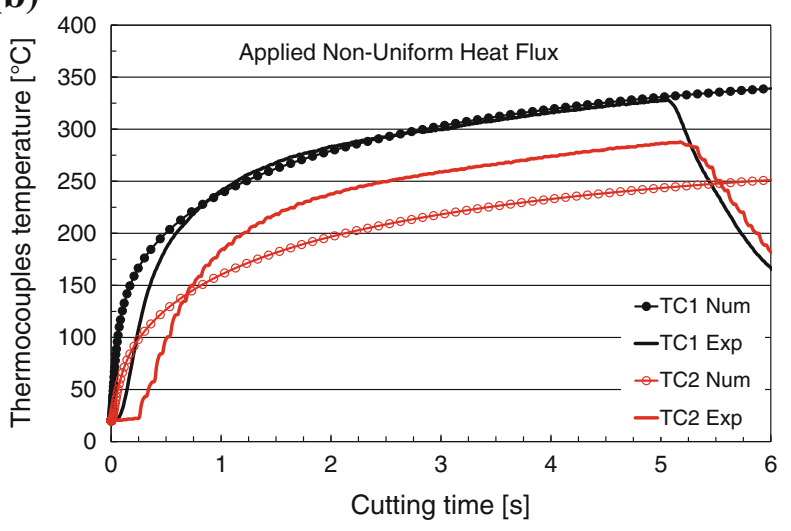

Fig. 17 Experimental temperature versus numerical temperature evolution at the thermocouples

sliding velocity and contact area to estimate the applied heat flux at the cutting face of the insert. The interface parameters are extremely difficult to estimate only by experimental means because of the high thermomechanical loading applied to the tool-chip interface during machining (high contact pressure, high temperature, intense friction, etc.). From the performed modelling several concluding remarks can be drawn:

1. The chip formation process simulated with the firststep model allows obtaining stabilized cutting forces, accurate chip morphology as well as chip flow direction. Different tool-chip interface parameters can also be estimated. It has been shown that the predicted feed force is underestimated compared to the experimental one. This is due to the relative helical motion between the tool and workpiece, which was represented by circular motion in the first-step FE model.

2. Numerical simulation of the chip formation process over few milliseconds (about $1.8 \mathrm{~ms}$ ) of the cutting time with the first-step FE model is achieved in about 8 days. It has been shown that this is not sufficient to obtain heat diffusion into the insert up to embedded thermocouples in reasonable CPU time only with this thermomechanical calculation.

3. Using contact pressure, interface sliding velocity and contact area, obtained from the first-step calculation, has allowed estimation of applied thermal load at the tool rake face used in the second-step FE model.

4. The fully thermal analysis performed with the secondstep FE model allows obtaining the temperature and heat flux fields in the insert and their evolution over few seconds of cutting time (about $5 \mathrm{~s}$ ). This time corresponds to the cutting duration of the machining test.

5. The applied heat flux at the contact zone of the insert is a critical for a good prediction of the heat diffusion into the insert. So using applied uniform or nonuniform heat flux has given different temperature and heat flux fields.

6. The temperature at TC1 is well predicted using the applied non-uniform heat flux. However, the temperature at TC2 is underestimated in the two cases (uniform and non-uniform applied heat fluxes). This is attributed to the underestimation of the contact area by the first-step FE model. Since the second thermocouple is more distant from the tool-chip interface, where heat generation by friction and plastic deformation occurs, predicted temperature at TC2 is less than the measured one. Improvement of the first-step FE calculation would give a more accurate temperature at TC2. However the gap between predicted and experimental temperatures would be much reduced if embedded thermocouples are closer to the cutting face. But in practice this can weaken the cutting tool if holes of thermocouples are closest to the cutting face.

Finally, it can be concluded that the proposed original strategy allows estimating non-uniform distributions of the tool-workpiece interface parameters, which are extremely difficult to obtain by experimental means. The critical point in the proposed approach lies in the first thermomechanical calculation, which determines de reliability of the second thermal calculation. However the possibility to perform calculations in reasonable time has been highlighted in this study.

\section{References}

1. Molinari A, Moufki A (2008) The Merchant's model of orthogonal cutting revisited: a new insight into the modelling of chip formation. Int J Mech Sci 50:124-131

2. Ozlu E, Budak E, Molinari A (2009) Analytical and experimental investigation of rake contact and friction behaviour in metal cutting. Int J Mach Tools Manuf 49:865-875 
3. Xie JQ, Byoumi AE, Zbib HM (1996) A study on shear banding in chip formation of orthogonal machining. Int $\mathrm{J}$ Mach Tools Manuf 36:835-847

4. Pawade RS, Sonawane HA, Joshi SS (2009) An analytical model to predict specific shear energy in high-speed turning of Inconel 718. Int J Mach Tools Manuf 49:979-990

5. Moufki A, Molinari A, Dudzinski D (1998) Modelling of orthogonal cutting with a temperature dependent friction law. J Mech Phys Solids 46(10):2103-2138

6. Grzesik W (2006) Composite layer-based analytical models for tool-chip interface temperatures in machining medium carbon steels with multi-layer coated cutting tools. J Mater Process Technol 176:102-110

7. Komanduri R, Hou ZB (2000) Thermal modelling of the metal cutting process-part I: temperature rise distribution due to shear plane heat source. Int J Mech Sci 42:1715-1752

8. Komanduri R, Hou ZB (2001) Thermal modelling of the metal cutting process-part II: temperature rise distribution due to frictional heat source at the tool-chip interface. Int J Mech Sci 43:57-88

9. Komanduri R, Hou ZB (2001) Thermal modelling of the metal cutting process-part III: temperature rise distribution due to the combined effects of shear plane heat source and the tool-chip interface frictional heat source. Int J Mech Sci 43:89-107

10. Ceretti E, Lucchi M, Atlan T (1999) FEM simulation of orthogonal cutting: serrated chip formation. J Mater Process Technol 95:17-26

11. Guo YB, Yen DW (2004) A FEM study on mechanisms of discontinuous chip formation in hard machining. J Mater Process Technol 155-156:1350-1356

12. Hua J, Shivpuri R (2004) Prediction of chip morphology and segmentation during the machining of titanium alloys. J Mater Process Technol 150:124-133

13. Marusich TD, Ortiz M (1995) Modelling and simulation of highspeed machining. Int J Numer Methods Eng 38:3675-3694

14. Mabrouki T, Girardin F, Asad M, Rigal J-F (2008) Numerical and experimental study of dry cutting for an aeronautic aluminium alloy (A2024-T351). Int J Mach Tools Manuf 48:1187-1197

15. Calamaz M, Coupard D, Girot F (2008) A new material model for 2D numerical simulation of serrated chip formation when machining titanium alloy Ti-6Al-4 V. Int J Mach Tools Manuf 48:275-288

16. Sima M, Özel T (2010) Modified material constitutive models for serrated chip formation simulations and experimental validation in machining of titanium alloy Ti-6Al-4 V. Int J Mach Tools Manuf 50:943-960

17. Hua J, Shivpuri R (2004) Prediction of chip morphology and segmentation during the machining of titanium alloys. J Mater Process Technol 150:124-133

18. Grzesik W (2006) Determination of temperature distribution in the cutting zone using hybrid analytical-FEM technique. Int $\mathrm{J}$ Mach Tools Manuf 46:651-658

19. Ulutan D, Lazoglu I, Dinc C (2009) Three-dimensional temperature predictions in machining processes using finite difference method. J Mater Process Technol 209:1111-1121

20. Lazoglu I, Altintas Y (2002) Prediction of tool and chip temperature in continuous and interrupted machining. Int $\mathrm{J}$ Mach Tools Manuf 42:1011-1022

21. Atlati S, Haddag B, Nouari M, Zenasni M (2011) Analysis of a new segmentation intensity ratio "SIR" to characterize the chip segmentation process in machining ductile metals. Int $\mathrm{J}$ Mach Tools and Manuf 51(9):687-700

22. Limido J, Espinosa C, Salaün M, Lacome JL (2007) SPH method applied to high speed cutting modelling. Int $\mathrm{J}$ Mech Sci 49:898-908
23. Kagnaya MT (2009) Contribution à l'identification des mécanismes d'usure d'un WC-6\%Co en usinage et par une approche tribologique et thermique. PHD Thesis of Ecole Supérieur des Mines de Paris

24. Bono M, Nib J (2006) The location of the maximum temperature on the cutting edges of a drill. Int $\mathrm{J}$ Mach Tools Manuf 46:901-907

25. Liu GJ, Tan G, Li G (2009) Experiment, modeling, and analysis for temperature field of milling insert. Int J Adv Manuf Technol 40:63-67

26. Stephenson DA, Jen T-C, Lavine AS (1997) Cutting tool temperatures in contour turning: transient analysis and experimental verification. Trans ASME 119:494-501

27. Liu J, Chou YK (2007) Cutting tool temperature analysis in heatpipe assisted composite machining. Trans ASME 129:902

28. Tieu AK, Fang XD, Zhang D (1998) FE analysis of cutting tool temperature field with adhering layer formation. Wear 214:252-258

29. Ramesha M, Seetharamua KN, Ganesanb N, Kuppuswamy G (1999) Finite element modeling of heat transfer analysis in machining of isotropic materials. Int $\mathbf{J}$ Heat Mass Transf 42: 1569-1583

30. Chang CS (2007) Prediction of the cutting temperatures of stainless steel with chamfered main cutting edge tools. J Mater Process Technol 190:332-341

31. Filice L, Umbrello D, Beccari S, Micari F (2006) On the FE codes capability for tool temperature calculation in machining processes. J Mater Process Technol 174:286-292

32. Umbrello D, Filice L, Rizzuti S, Micari F, Settineri L (2007) On the effectiveness of finite element simulation of orthogonal cutting with particular reference to temperature prediction. J Mater Process Technol 189:284-291

33. Carvalho SR, Lima e Silva SMM, Machado AR, Guimaraes G (2006) Temperature determination at the chip-tool interface using an inverse thermal model considering the tool and tool holder. J Mater Process Technol 179:97-104

34. Rech J, Kusiak A, Battaglia JL (2004) Tribological and thermal functions of cutting tool coatings. Surf Coat Technol 186:364-371

35. Lazard M, Corvisier P (2004) Modeling of a tool during turning - analytical prediction of the temperature and of the heat flux at the tool's tip. Appl Thermal Eng 24:839-849

36. Battaglia JL, Batsale JC (2000) Estimation of heat flux and temperature in a tool during turning, Inv Probl Eng 1-23

37. Deform ${ }^{\mathrm{TM}}$-3D Version 10.1 (2010) Scientific Forming Technologies Corporation

38. Abaqus ${ }^{\mathrm{TM}}$ —Standard Version (2009) Documentation for version 6.9. Dassault Systems Simulia

39. Barlier C, Procédé pour la détection directe, en continu, de l'usure des outils de coupe par sonde électrique incorporée, Brevet BARLIER no. 8707969 (France) and 88-470021-2 (Europe)

40. Barlier C, Lescalier C, Muller J.M, Delebecque B (1996) Mesure en continu de l'usure des outils de coupe par microsondes incorporées-acquisition par capteur de temperature appliquee a la recherche de l'usure-le système ACTARUS ${ }^{\circledR}$, First International Conference on Integrated Design and Manufacturing in Mechanical Engineering, Nantes

41. Jaspers SPFC, Dautzenberg JH, Taminiau DA (1998) Temperature measurement in orthogonal metal cutting. Int J Adv Manuf Technol 14:7-12

42. Ueda T, A1-Huda M, Yamada K, Nakayama K (1999) Temperature measurement of CBN tool in turning of high hardness steel. Annals of the CIRP $48 / 1$

43. Müller B, Renz U (2003) Time resolved temperature measurements in manufacturing. Measurement 34:363-370 
44. Sutter G, Ranc N (2007) Temperature fields in a chip during highspeed orthogonal cutting - an experimental investigation. Int $\mathrm{J}$ Mach Tools Manuf 47:1507-1517

45. Johnson GR, Cook WH (1985) Fracture characteristics of three metals subjected to various strains, strain rates, temperatures and pressures. Eng Fract Mech 21:31-48
46. Jaspers SPFC, Dautzenberg JH (2002) Material behaviour in conditions similar to metal cutting: flow stress in the primary shear zone. J Mater Process Technol 122:322-333 